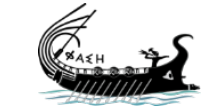

journal.phaselis.org
PHASKLIS

Issue IV (2018)
Disiplinlerarası Akdeniz Araştırmaları Dergisi

Journal of Interdisciplinary Mediterranean Studies

\title{
MÖ 425 - 300 Yılları Arasında Rhodos'un Doğu Akdeniz Ekonomisindeki Etkisi ve Adanın Siyasi Yapısı
}

The Impact of Rhodes Over the Economy of Eastern Mediterranean Sea and Her Political Structure (425-300 BC)

\section{Muzaffer DEMiR}

open $\bigcirc$ access journals

The entire contents of this journal, Phaselis: Journal of Interdisciplinary Mediterranean Studies, is open to users and it is an 'open access' journal. Users are able to read the full texts, to download, to copy, print and distribute without obtaining the permission of the editor and author(s). However, all references to the articles published in the e-journal Phaselis are to indicate through reference the source of the citation from this journal.

Phaselis: Journal of Interdisciplinary Mediterranean Studies is a peer-reviewed journal and the articles which have had their peer reviewing process completed will be published on the web-site (journal.phaselis.org) in the year of the journal's issue (e.g. Issue III: JanuaryDecember 2017). At the end of December 2016 the year's issue is completed and Volume IV: January-December 2018 will begin.

Responsibility for the articles published in this journal remains with the authors.

Citation M. Demir, “MÖ 425 - 300 Yılları Arasında Rhodos'un Doğu Akdeniz Ekonomisindeki Etkisi ve Adanın Siyasi Yapısı". Phaselis IV (2018) 161-175. DOI: 10.18367/Pha.18010

Received Date: 21.03.2018 | Acceptance Date: 16.05.2018

Online Publication Date: 04.06.2018

Phaselis Research Project

www.phaselis.org 


\title{
MÖ 425 - 300 Yılları Arasında Rhodos'un Doğu Akdeniz Ekonomisindeki Etkisi ve Adanın Siyasi Yapısı
}

\author{
The Impact of Rhodes Over the Economy of Eastern Mediterranean Sea and Her \\ Political Structure (425-300 BC)
}

\begin{abstract}
Muzaffer DEMIR*
Öz: Rhodos, erken dönemlerden itibaren güçlü bir askeri donanmaya ve deniz ticaretiyle uğraşan tüccar sınıfına sahip ola gelmiştir. Rhodos özellikle doğuya doğru Güney Anadolu sahilleri ve Levant üzerinden Mısır'a, batıya doğru Kiklad adaları ve kent devletleri, kuzeye doğru Küçük Asya kıyı adaları ve kent devletleri ve Karadeniz'e kadar uzanan özellikle hububat ticaret yolları üzerinde merkezi bir stratejik konumu elinde tutmuştur. Bu durum adanın liman gelirlerine ve refah seviyesine yansımıştır. Güçlü olduğu VIII. yüzyılın ilk yarııı ve III. yüzyııın sonlarında bölgesinde deniz güvenliğini, hâkimiyetini ve ticaretini elinde tutabilmiştir. Ancak Klasik Dönem V. yüzyılda Persler, Spartalılar ve Atinalılar gibi bölgenin büyük güçlü devletleri arasında denge politikaları sayesinde ayakta kalmayı başarmıştır. Rhodos'un özellikle IV. yüzyılda kendi içinden de destek alan bu büyük güçlerin etkisi altında sık sık taraf değiştirdiğine ve hatta Atina'nın desteklediği demokrasiden, Pers ve Spartalıların desteklediği oligarşi yönetimine kaydığına şahit olmaktayız. Rhodos, IV. yüzyılın sonlarına doğru ticari açıdan avantajı olacağını düşünerek Büyük İskender sonrası Diadokhoi krallarının her biri ile dostluklar kurmaya çalışmış ve onların birbirleriyle olan savaşlarına katılmamaya çaba harcamışıı. 305 yılında Makedonya kralı I. Antigonos'un oğlu Demetrios'un ısrarlarına rağmen, kendi ticareti ve gelirleri açısından önemli bir yer olan Mısır kralı I. Ptolemaios'un safında yer almış ve büyük bir kuşatma sonucunda teslim olmak zorunda kalmıştır.
\end{abstract}

Anahtar sözcükler: Rhodos, Ticaret, Politika ve Klasik Dönem

Abstract: Rhodes, from the earlier times onwards, had continued to maintain a powerful military navy and a trading class. From a strategical point of view, she was especially at the center of grain trade extending towards the east, from the southern coasts of Anatolia to the Levantine and then to the Egypth, towards the West to the Cylades and to the the important city-states of Greece as well as towards the North, to the coastal islands and the cities of Asia Minor and finally ending with the city-states of Black Sea. This position of the island seems to have reflected itself on her welfare. During the first half of the VIII ${ }^{\text {th }}$ century and the last quarter of the $\mathrm{IV}^{\text {th }}$ century when she was very strong, she held the control, security and the trade of the sea in her region. Yet, she seems to have succeeded in standing on her own during the $\mathrm{V}^{\text {th }}$ century BC by watching out the policy of balance among the big powers such as Athens, Sparta and Persia. Rhodes appears to have often changed sides during the $\mathrm{IV}^{\text {th }}$ century BC by means of the support from the interior factions who collaborated with the foreign powers; she adopted the rule of democracy by the intervention and support of Athens and the rule of oligarchy by those of Persia and Sparta. Towards the end of the IV ${ }^{\text {th }}$ century BC, having thought it useful from a commercial point of view, she strove to establish friendships with the kings of Diadochoi after the death of Alexander the Great and not to interfere in the wars among those kings. Despite this, she was obliged to make alliance with the Egyptian king Ptolemy I due to her close trade relations when Demetrius, the son of Antigonus I, insisted on making Rhodes to take side with himself. As a result of this, she was put under a heavy blockade by Demetrius and had to surrender to him in 305 BC.

Keywords: Rhodes, Trade, Politics and Classical Period

* Prof. Dr., Muğla Sıtkı Koçman Üniversitesi, Edebiyat Fakültesi, Tarih Bölümü, dmuzaffer@mu.edu.tr Aksi belirtilmediği sürece tarihler milattan öncesine aittir. 


\section{Giriş}

Rhodos'un deniz kuvvetleri açısından Arkaik Dönem'de VIII. yüzyılın ilk yarısında deniz egemenliği (thalassokrasia) kurduğu bilinmektedir ${ }^{1}$. Klasik Dönem (500-300) Rhodos donanması hakkında detaylı bilgiler bulunmamasına rağmen, eldeki kaynaklardan bazı çıkarımlar yapılabilir. Aşağıda bahsedeceğimiz üzere, genelde V. yüzyılda Rhodos denizcilerinin ve kara güçlerinin üstünlügünden bahsedilmektedir (Thuk. VIII. 44. 1). Rhodoslular, 480 yılında Karia kıyılarında yaşayan Dorlar ve Koslularla birlikte Hellas'ı istila seferine çıkan Pers kralı Kserkses'in donanmasına 40 gemiden oluşan bir destek sağlamışlardı․ Bunun yanında Rhodos, IV. yüzyılda acil durumlarda 10 gemiden oluşan bir donanma birliği oluşturabilmiş ve aşağıda da bahsedeceğimiz üzere Sosyal Savaş (357/6-355/4) esnasında 100 gemiden oluşan Atina'ya karşı ayaklanma donanmasına katkıda bulunmuştur ${ }^{4}$. Demosthenes'in bir mahkeme konuşması (XIII. 1) üzerine düşülen skholion'da da, Sosyal Savaş sırasındaki Rhodos deniz gücünden bahsedilmektedir. Bu deniz gücü sayesinde Rhodos Sosyal Savaş'ta başarılı olmuştur. Aristoteles'in Sosyal Savaş dönemiyle ilgili olarak bahsettiği, Rhodoslu trierarkhoi'nin üstlendiği görevler Atina modelinde çalışan görkemli bir deniz gücüne işaret etmektedir ${ }^{5}$. Aristoteles'i bu konuda teyit eden Strabon (XIV. 2. 5), Rhodos'ta erzak eksiğini tamamlayan kamu hizmetlileri sınıfı (leitourgiai) bulunduğundan, hem fakirlerin gereksinimlerini sağladığını, hem de kentde özellikle donanmanın kuvvetlenmesi için yararlı adamların eksilmediğini vurgulamaktadır. Buradan da Rhodosluların donanmalarına önem verdikleri ve sürekli olarak her türlü gereksinimlerini karşıladıkları anlaşılmaktadır. Vitruvius'un aşağıda aktaracağımız metninde de, 354 yılında Halikarnassos'a saldıran Rhodos donanmasının iyi donatıldığı özellikle vurgulanmaktadır. Yine aşağıda belirteceğimiz üzere, Rhodos'un 220 yılı itibariyle tekrar "denizlerin hâkimi" konumuna geldiği ve Byzantion'un Karadeniz'den gelen ticaret gemilerinden vergi almaya başlaması üzerine diğer devletlerin haklarını savunmak için Byzantion'a karşı savaşta liderliği ele aldığı görülmektedir ${ }^{6}$. Bunun yanında 190 yılında tek bir yıl içinde Seleukos kralı III. Antiokhos'a karşı 75 savaş gemisinden oluşan bir donanma gücü oluşturabildiği gerçeği bulunmaktadır? .

Bütün bu veriler dikkate alındığında, erken dönemlerden itibaren önemli bir askeri deniz gücüne sahip olan Rhodos, deniz ticaretinde de uzun süre bölgesindeki üstünlüğü eline almıştır. Rhodos'un ticari öneminin merkezinde onun stratejik coğrafi konumu yatmaktadır. Rhodos-Mısır hattı, kışın bile bütün yıl boyunca ticaretin yapılabildiği tek hat olma özelliğine sahip olmuştur (Dem. LVI. 30). Mısır, Levant ve Anadolu'nun güney sahillerinden gelen gemiler, genelde Rhodos'tan geçmek gereği duymaktaydılar. ${ }^{8}$ Rhodos, üç ana hububat sağlayıcı merkezin ikisi, kuzeyde Kırım ve güneyde Mısır arasında yer aldığından bu merkezlerin en iyi alıcıları olan, Atina

1 Myres 1906, 88, 125; Ball 1977, 321; Abulafia 2014. Rhodos'un Akdeniz'deki politik gücünün artışı ve hâkimiyet alanının genişlemesi hususundaki kronolojik süreç hakkında bk. Magie 1950, 71-2; Rhodos'un özellikle MÖ IV. yüzyılın sonlarına doğru sergilemiş olduğu ekonomik gelişme hakkında bk. Berthold 1984, 37; Rhodos deniz gücünün MÖ III. yüzyıldaki gelişimi konusunda ayrıca bk. Gabrielsen 1997, 61-2.

Diod. XI. 3. 8.

Diod. XIX. 77. 2; Arr. Anab. II .20

Diod. XVI. 7. 3, 21. 2; daha detaylı bilgi için ayrıca bk. Arslan 2010, 163 vdd.

Hornblower 1982, 212.

Polyb. IV. 47. 1; ayrıca bk. Cawkwell 1981, 41; Arslan 2010, 251 vdd.

Liv. XXXVII. 9. 5, 12. 9, 16. 3, 22. 3-4.

Rodos Mısır'dan Karadeniz ve Batı Akdeniz'e uzanan özellikle hububat ticaretinde stratejik bir öneme sahip olmuştur (Starr 1989, 53; Gabrielsen 1997, 71). İskenderiye'deki kazılardan elde edilen seksenbeş bin yüzotuz dört amfora damgasından seksen bini Rodos'a aittir (Gibbins 2001, 276, Tablo 10.1, 281-83, 292-3, Tablo.10A1). 
gibi önemli Hellen kentleri, Kyklades adaları ve Küçük Asya kıyı kentlerine kolay erişimin sağlanabildiği bir konumdaydı. Strabon'un da belirttiği gibi (XIV. 2. 10), Rhodos, erken dönemlerden itibaren denizlerdeki başarısı sayesinde ekonomik açıdan zengin bir yer olmuştur; Doğu Akdeniz ve Mısır ticaret yolu üzerinde bulunması ve Atina gibi önemli Hellen kentlerine sağlanan hububat ticaretinin buradan geçmesi konumunu zengin kıldığından, özellikle liman vergilerinden elde ettiği gelirler çok yüksek seviyelere ulaşmıştır ${ }^{9}$. IV. yüzyılın sonlarına atıfta bulunan Diodoros (XX. 81), Rhodosluların gelirlerinin çoğunu Mısır'a yelken açan tüccarlardan elde ettiklerini ve kentin büyük oranda bu krallık üzerinden geçimini sağladığını bildirerek bu veriyi teyit etmektedir. Rhodosluların V. yüzyılın ikinci yarısı Atina Vergi Listeleri'ndeki kayıtlarda normal şartlarda diğer Karia kentlerine oranla çok büyük miktarlarda vergi ödeyebildikleri ortadadır ${ }^{10}$. IV. yüzyıl ortalarında adada arkadaşlarıyla birlikte oligarşik bir yönetim kuran Hegesilokhos'un görkemli bir hayat sürdüğü söylenmektedir ${ }^{11}$. Ayrıca Rhodos sikkeleri belli bir dönem Karia Hekatomnos hanedanlığı tarafından taklit edilmiştir ${ }^{12}$. Bütün bunlar Rhodos'un deniz ticaretine dayalı ekonomik gücünün göstergesidir ve bu ekonomik gücü sayesinde tarih içinde üstün bir deniz kuvvetine sahip olmaya devam etmiştir.

Bu bağlamda Rhodos, deniz ticaretiyle ilgili işlerini iyi organize etmiştir. Deniz ticareti işlerinde yatırım yapmak için bol miktarda kapitali elinde tutan kendi bankerlerine sahiptir. Bunlar, deniz ticareti yapmak isteyen herkese kolaylıkla belirli bir faiz karşılığında kredi imkânı sunmuşlardır. Çok daha önemli olan, uluslararası tüccarların ağılıklı olarak ticareti yürüttüğü Atina veya Korinthos gibi deniz ticaretinde güçlü kent devletleriyle kıyaslandığında Rhodoslu tüccarların çok sayıda deniz ticaret gemilerine sahip olmasıdır. Yük taşımaya uygun ve hazır olan Rhodos gemilerinin IV. yüzyıl itibariyle yerleşik dünyanın her yerine ticaret için yelken açtığı bildirilmektedir, onlara Suriye, Fenike, Kilikia ve Pamphylia limanlarında rastlanmaktadır. Rhodos, bu ticaretle uğraşan çok sayıda deniz tüccarını ve deniz ticaretine yönelik finansal yatıımını korumak için denizlerin güvenlik altına alınmasına ve Rhodos Denizcilik Yasaları derlemelerinin çıkarılmasına öncülük etmiştir ${ }^{13}$. Gemileri Karadeniz ve Mısır'a seyehat etmiş, kendileri ve komşularının üzüm tarlalarından elde edilen şarabı taşıyarak hububatla geri dönmüşlerdir. Mısır trafiği büyük oranda onların elinde kalmıştır, çünkü çok sayıda Rhodos şarap amfora tutakları Mısır'da arkeologlar tarafından gün yüzüne çıkarılmıştır. Karadeniz'den gelen erzaklar Ege'nin tamamı üzerindeki müşterilere satılmış olsa da, bunların büyük miktarının Rhodos'a gittiği kesindir. Aşağıda da belirteceğimiz üzere, Karadeniz bölgesi Rhodos üzerinden şarap ithal etmiştir, orada keşfedilen binlerce amfora tutaklarından bunu bilmekteyiz. Hiç şüphesiz karşılığında adaya hububat göndermişlerdir. Rıhtımlarına gelen hububatın bir kısmı, adanın çiftlikleri büyük oranda bağcılığa verildiğinden, kendileri ve komşularının nüfusunu beslemek için kullanılmıştır. Ancak hububatın çoğu Atina, Küçük Asya'nın kıyı kentlerine ve Ege adalarına gemilerle transfer edilmiştir ${ }^{14}$.

Atina merkezli antik kaynaklar Rhodos'un özellikle V. yüzyılın son çeyreğinden itibaren Mısır veya Karadeniz üzerinden Hellen kentlerine hububat ticareti açısından kritik bir rol üstlendiğini göstermektedir. Bu kritik rol çok daha önceden başlamış olabilirdi. Ancak yukarıda belirttiğimiz dönem öncesi ile ilgili detaylı bir antik kaynak günümüze kadar ulaşamamıştır. Spartalılar,

9 Ayrıca bk. Dem. LVI; Lyk. I. 14, 18-19, 21, 55, 70, 121; Polyb. IV. 47. 1; ayrıca bk. Garnsey 1988, 140, 152, 157.

10 Meiggs 1972, 554-5; Meritt et al. Atina Vergi Listeleri I, 224-225.

11 Athen.deip. X. $444 \mathrm{E}-445 \mathrm{~A}=$ FgrHist $115 \mathrm{~F} 121$.

12 Hornblower 1982, 129.

13 Roma kanun kodu I. yüzyılda Roma dünyasında yaygın olarak kullanılmaya başlanmıştır (Kurul 2014). Rhodos adası IV. yy. boyunca korsanlara karşı savaşında emperyal bir kimlik inşa etmiştir (Braund 1993, 203).

14 Antik kaynaklar ve tartışma için bk. Casson 1954, 171-4. 
Peloponnesos savaşlarının (431-404) ikinci aşamasında, 413 yılının yazında Atinalıları Atina kent surları içinde kuşatarak ve onları Attika'nın maden ve tarım kaynaklarından mahrum bırakarak Dekelea'yı etkili bir şekilde kuşatma altına almışlardır. Thukydides'e göre (VII. 27-28. 1), Dekelea'nın uzun vadeli işgali etkili olmuş ve Atinalıların karadan erzak temin etmeleri sıkıntıya girmiştir ki, bunları 431 yılında savaşın başında Euboia Adası'na transfer etmişlerdi (Thuk. II. 14. 1). Bunun sonucunda Atinalılar, tam anlamıyla deniz üzerinden ticarete bağımlı hale gelmişlerdir. Bu arada Atina'ya hububat sağlayan merkezlerden birisi olan Sicilya kentleri ${ }^{15}, 413$ yllında Atina'ya karşı ayaklanmıştır. 412 yılında Euboia, Lesbos, Khios ve Ertyhrai, Spartalılara Lakedaimon yardımı karşılığında aktif bir şekilde yardım teklifinde bulunmuşlardır. 411 yılı itibariyle sadece Euboia Atinalılar karşısında direncini korumayı başarmış ve Rhodos da Sparta'nın yanında Atina'ya karşı ayaklanma girişiminde bulunmuştur. Thukydides, bu Rhodos ayaklanmasını Sparta'nın liderliğini yaptığı Peloponnesosluların kışkırttığını şöyle açıklamaktadır (VIII. 44. 1-3): "Peloponnesoslular [Lakedaimonialılar veya Spartalılar], Rhodos'ta bazı önde gelen adamların daveti üzerine ve deniz adamlarının ve kara güçlerinin sayısı açısından güçlü bir adayı kazanmayı ümit ederek ve aynı zamanda [Ionia'nın Pers satrapı] Tissaphernes'ten para ricasında bulunmak zorunda olmadan kendi konfederasyonlarından donanmalarını oluşturabileceklerini de düşünerek, artık Rhodos'a yelken açma konusundaki kararlııklarını ortaya koymuşlardır. [2] Onlar buna uygun olarak aynı kıs ayında Knidos'tan yelken açmışlar ve ilk önce 94 gemiyle Rhodos topraklarındaki Kamiros'ta karaya ayak basmışlardır. Bu durum yerleşimciler tarafında büyük bir panik yaratmıştır ki, bunlar [Atina'ya karşı] entrikacılarla birlikte hareket etmeyen insanlardır. Özellikle yerleşim yerleri surla çevrili olmadığından kaçmayı tercih etmişlerdir. Buna rağmen Lakedaimonialılar, daha sonra Lindos, lalysos ve diğer yerleşimlerin iskâncılarını bir araya toplamıştır. Rhodoslular Atinalılara karşı ayaklanma konusunda ikna edilmiş ve ada Peloponnesoslular tarafına geçmiştir. [3] Bu arada Atinalılar telaşa kapılmışlar ve onları engellemek için donanmalarıyla Samos adasından yelken açmışlar ve adanın açıklarına gelmişlerdir, ancak geç kaldıklarını fark ederek o an için Kkalke'ye, oradan da Samos'a yelken açmışlardır. Sonuçta, Khalke, Kos ve Samos adalarından yelken açarak Rhodos'a karşı savaş yürütmüşlerdir". Böylelikle Atinalıların, hububata ihtiyaç duydukları Spartalılara karşı savaşın kritik döneminde Rhodos gibi stratejik yerlerdeki isyanları bastırmaya çalışıkları görülmektedir. Onların Sicilya ve Euboia'yı kaybettikleri bir dönemde, Karadeniz ve Mısır gibi diğer yerlerden hububat ve ürün ihtiyacını karşılamaları çok daha elzem bir hale gelmiştir. Bu sebeple Rhodos'un Mısır'dan Atina'ya ithal edilecek hububat açısından kaybedilmemesi gerekmekteydi. Ancak Atinalıların bunda başarıı olamadıkları ve bu sebeple yüzlerini Boğazlar ve Karadeniz üzerinden gelecek hububata çevirmek zorunda kaldıkları anlaşılmaktadır.

Yukarıda değindiğimiz Atina'ya karşı ayaklanma sonrasında Sparta komutanı Lysandros'un Rhodos ve çevresindeki ablukayı devam ettirdiğine ve kontrollerini sıklaştırdığına dair deliller bulunmaktadır. Biz bu bilgileri Thukydides'in eserinin devamı olan Ksenophon'un Hellenika adlı eserinin satır aralarından öğrenmekteyiz. Ksenophon şöyle aktarmaktadır (Hell. II. 1. 17): "Lysandros Rhodos'tan Ionia kıyısı boyunca Hellespontos'a yelken açmıştır; bunun sebebi [bu bölgede] Lakedaimonialılara karşı ayaklanmış olan kentler karşısında harekete geçmek ve [Atina'ya] hububat taşıyan gemileri engellemek olacaktır". Bu metinden de anlaşılacağı üzere Spartalılar, Ionia ve Karia bölgelerindeki kentleri ayaklandırırken Atinalılar boş durmamış, yine gerekli hububat ve erzak sağlama stratejisi açısından önemli olan Hellespontos (Çanakkale Boğazı) bölgesindeki kentleri Spartalılara karşı ayaklanmaya ve kendi saflarına çekmeye teşvik etmişlerdir. Lysandros, Rhodos ve çevresinden Atina'ya hareket edebilecek hububat ve çeşitli ürünler

15 Thuk. VI. 24 
taşıyan gemilerin önünü kesmeye yönelik operasyonlarda bulunurken, bunun yetersiz olduğu görülmüş, Karadeniz ve Boğazlar üzerinden de Atina'ya erzak taşıyan gemilerin önünün kesilmesi zorunluluğu doğmuştur. Spartalıların Rhodos ve Boğazlar üzerinden erzak gelmesini engelleme sebebi kuşatma altındaki Atina'yı kıtlığa sevk etmek ve teslim olmaya zorlamaktır. Lysandros, nihayetinde açık denizlerde baş edilemeyeceğini anlayarak Atina donanmasını Hellespontos Boğazı'nda köşeye sıkıştırmış ve 405 yılında, bölgenin Pers satrapı Pharnabazos'un da karadan Pers parası, asker gücü ve lojistik desteği ile birlikte, Aigospotamoi'de Atina donanmasını yenilgiye uğratmayı başarmıştır. Böylelikle denizden erzak sağlayamayan kuşatma altındaki Atina kenti teslim olmak zorunda kalmıştır ${ }^{16}$.

Sparta kralı Agesialus, Atinalıların 404 yılında teslim olmasından sonra, bu sefer daha önceden Atina'ya karşı ittifak yaptığı Perslere karşı Küçük Asya seferini 396 yılında başlatmıştır. Bunun sonucunda Sparta'nın, başlangıçta Persler tarafından da destek verilen Thebes, Korinthos, sonradan da Atina ve Argos kentlerine karşı 387 yılına kadar sürecek olan Korinthos savaşı gerçekleşecektir. Rhodosluların bu zaman zarfında Sparta boyunduruğu altında zor şartlarda yaşadıkları anlaşılmaktadır. Nitekim Rhodos'un bu sefer Sparta'ya karşı 396 veya 395 yazında ayaklandığı ve bu ayaklanma sırasındaki gelişmelerin 394 yılına kadar sürdüğü görülmektedir.

Diodoros (XIV. 79. 4-8), bu ayaklanmayla bağlantılı deniz savaşındaki dört sürece atıfta bulunmaktadır. Buna göre; (1) Spartalı nauarkhos Pharaks, 120 gemiyle Rhodos'tan hareket ederek Perslerle işbirliği içinde olan, yukarıda bahsettiğimiz 404 yılındaki Aigospotamoi yenilgisinden sonra hüküm giymekten korkup Kıbrıs'a sığınan tecrübeli Atinalı komutan Konon'u 40 gemiden oluşan Pers kralının donanmasıyla birlikte Kaunos'ta kuşatma altına almıştır; (2) Perslerin Anadolu satrapları Artaphernes ve Pharnabazos, büyük bir güçle Konon ve Kaunosluların yardımına gelmiş ve Pharaks Rhodos'a geri çekilmiştir; (3) bunun üzerine Konon 80 gemiyle Knidos yarımadasına yelken açmış, bu arada Rhodos halkı ayaklanmış, hububat gemileri ele geçirilmiş ve Sparta donanmasını göndermişlerdir, Konon Pers kralının donanmasıyla birlikte Rhodos'a kabul edilmiştir; (4) Kilikia ve Phoenikia'dan Konon'a yardım etmek için 60 gemi gelmiştir.

Burada da görüldüğü üzere şans eseri Mısır üzerinden bu sefer Sparta'ya hububat taşıyan gemilerin Konon tarafından ele geçirildiği görülmektedir. 395 yılının yazında da Rhodos'ta demokratik bir devrim meydana gelmiştir ${ }^{17}$. Rhodoslu demokratlar, artık Perslerin ve eskisi kadar gücü olmasa da Atina'nın stratejik çıkarları doğrultusunda hareket edeceklerdir ${ }^{18}$.

Buna rağmen Rhodos'a yönelik Sparta tehdidinin devam ettiği görülmektedir. IV. yüzyılın başlarından itibaren kendilerini toparlayan Atinalılar, bu sefer tek başlarına Ege Denizi'nde Sparta deniz gücünü daha da sınılandırmak için harekete geçmişlerdir. Atinalılar, Thrasybulos'un komutası altında 40 gemiden oluşan bir donanmayı Rhodos'a doğru 390 yılında yola çıkarmışlardır. Ksenophon bu donanmanın misyonunun Sparta müdahalesine karşı Rhodos'taki demokrat-

16 Ksen. Hell. II. 1. 25-26.

17 Panhellenik atletik oyunlardaki yiğitlikleri ile meşhur olan (Paus. VI. 7. 1-7) Diagorid ailesi oligarşik hanedanlığı bu süreçte son bulmuştur; Pharnabazos'un Rhodos ayaklanmasından sonra Timokrates isimli bir Rhodosluyu Hellas anakarasındaki Hellen kentlerine, Sparta'ya karşı birleşmeleri için yüklü bir para ile gönderdiği bildirilmektedir. Ksenophon reddetse de, Okshyrnkhos tarihçisi Atina'nın para teklifini kabul ettiğini yazmaktadır. Nitekim Atina da sonunda Sparta'ya karşı savaşa iştirak etmiştir. Atina'nın bu savaş sırasında Konon'un emri altındaki Pers donanmasına kamuya ait köle kürekçileri (hyperesiai), kiraladığı bilinmektedir (Tod 167; 197).

18 Rhodosluların Sparta'ya karşı ayaklanmasında yabancı güçlerin etkin bir müdahalesi olmadığı ve hatta bu iç ayaklanmanın demokrasi veya oligarşi taraftarı bütün Rhodosluların rızasıyla gerçekleştiği ileri sürülmektedir (Bruce 1961, 167). Ancak demokrasi taraftarı bir ayaklanma olma ihtimali de yüksektir. 
lara yardım etmek olduğunu, ancak bu plandan vazgeçildiğini şöyle bildirmektedir (Hell. IV. 8. 25-28): "Bu arada Atinalılar, Lakedaimonialıların denizlerde tekrar üstünlüğü ele geçirmek üzere olduklarına inanarak onlara karşı Steira demesinden Thrasybulos'u 40 gemi ile göndermiştir. 0 , yelken açtıktan sonra Rhodos'a gitme planlarından vazgeçmiştir. Bunun sebepleri arasında; bir taraftan bir kaleyi ellerinde tutmaları; onları desteklemek için gönderilmiş olan Teleutias'ın bir donanma ile orada bulunması sayesinde Lakedaimonialıların [Atinalıların] dostlarını kolayca cezalandıramayacağını anlamaları; kendi devletinin [Atina'nın] dost kentleri elinde tutması; girilen çok sayıda çatışmada muzaffer olmalarından onların [Rhodoslu müttefiklerin] düşmanın [Lakedaimonialıların] gücü altına düşmeyeceğini düşünmesi yatmaktadır ${ }^{\prime 19}$. Metinde de aktarıldığı üzere Thrasybulos, yelken açtıktan sonra, Sparta tehdidinin ortadan kalktığını görerek Rhodos'a sefer düzenlemenin gereksiz olduğuna karar vermiş ve bunun yerine geleneksel olduğu üzere ve daha faydalı olacağını düşünerek Hellespontos'a yelken açmıştır. Burada da Byzantion kentinin yönetimini oligarşiden demokrasiye çevirmeyi başarmış ve onlarla birlikte hareket ederek İstanbul Boğazı'ndan geçen gemiler üzerine onda birlik bir vergi koyarak Karadeniz üzerinden Ege'ye deniz ticaretini kontrol altına almaya çalışmışır (Ksen. Hell. IV. 8. 27). Burada onun temel amacının Atina'yı finansal sıkıntıdan kurtarmak için derhal para toplamak olduğu gözükmektedir. Atinalıların bu onda birlik vergi toplama işini yıllık olarak peşin para veren kişilere ihale etme olasılığı yüksektir (Ksen. Hell. IV. 8. 31-34). Benzer bir vergi Rhodos adasında limana uğrayan veya uğramaya zorlanan ticaret gemilerinden de toplanmış olabilirdi. Ancak bu siyasetin uzun vadeli olarak uygulanabilmesi mümkün değildi, çünkü çeşitli kent devletlerinin uluslararası tüccarlardan transit geçiş veya zorla liman vergisinin toplanmasını tekelleştirmeye yönelik teşebbüsleri diğer devletlerinin baskısıyla engellenebilirdi ${ }^{20}$. Nitekim Byzantion finansal zorluklar yüzünden III. yüzyılın sonlarında boğazdan geçen gemilerden zorla ithalat vergisi toplama teşebbüsünde bulunmuş ve bu da Rhodos ile savaşa neden olmuştur.

Aslında bu savaş Karadeniz üzerinden gelen ticaretin de Rhodos açısından ne kadar önemli olduğunu ortaya koymaktadır. Polybios, eserinin 38-45. bölümlerinde bu savaş hakkında bilgi verirken aynı zamanda Karadeniz üzerinden Akdeniz dünyasına ticareti yapılan ürünlere atıfta bulunmaktadır. Ona göre, ticareti yapılan bu ürünler arasında bol miktarda büyük baş hayvan derisi ve köleler gibi temel ürünler yanında, bal, bal mumu, amforalar içinde tuzlanmış balık (hamsi de dâhil) gibi lüks sayılabilecek ürünler de yer almaktaydı. Karadeniz kentleri bu ürünlerin karşılığında zeytinyağı ve her türlü şarap satın almaktaydı. İyi veya kötü hasata göre de her iki yönde hububat ticareti yapılmaktaydı (Polyb. IV. 38). Dolayısıyla Karadeniz üzerinden gelen bu ürünlerin Rhodos limanlarına uğraması da söz konusudur. Diğer taraftan Rhodos yukarıda da belirttiğimiz üzere Karadeniz'e ürettiği şarabın fazlasını satmış olmalıdır²1. Bunun yanında

19 Bu sefer oligarşi taraftarları, dış destek olmaksızın muhtemelen 391 yılının bahar başlarında başarıı bir darbe gerçekleştirmişlerdir. Yönetimlerini güçlendirmek ve Atinalıların adayı kontrol etmesini önlemek için Spartalıların müdahalesine göz yummuşlardır. Rhodoslu demokratlar, Ekdikos'un komutası altındaki Sparta kuvvetleri ulaşmadan önce yaz sonu veya sonbahar başında, 391 yılında ayaklanmışlardır. Uzun süren bir iç savaştan sonra şimdi Sparta amirali Teleutias'ın desteğini alan oligarşi taraftarları, yavaş yavaş kendilerini toparlamışlar ve Atinalıların 389 yılı yazında demokratlara yardımının gecikmesi sonucunda nihai zafere ulaşmışlardır (David 1984, 283-4).

20 Bu onda birlik verginin bir devlet tarafından empoze edilmesi, uluslararası ticaret sınıfının çıkarlarına ters düştüğünden müsaade edilmeyebilirdi. Lakedaimonialıların, Atinalıların bu vergiyi empoze etmesi ve Khalkedon'u ele geçirmesi karşısında hızla harekete geçtiklerini görmekteyiz (Ksen. Hell. IV. 8.31-34).

21 Athenaios, Rhodos sularında yakalanan sardunya gibi taze küçük balıkların (aphye) en iyisi olduğunu bildirmektedir (deip. VII. 285 B, 285 E; IV. 135 A). Karadeniz hamsisi gibi bu küçük Rhodos balıklarının tuzlanıp, soslanarak ticaretinin yapıldığına dair ise bir kaynak bulunmamaktadır. 
Rhodos'un yerel cam kaplar üretiminin VI. yüzyılın son çeyreğinde başlayarak V. ve IV. yüzyıl boyunca devam ettiği ve ticaretinin yapıldığı bilinmektedir ${ }^{22}$. Bu camdan ürünlerin Karadeniz'e de ticareti söz konusu olmalıdır. Polybios'un ilgili kaynağı II. yüzyılın başlarına, Hellenistik Dönem'e atıfta bulunsa da, Karadeniz'den ve Karadeniz'dekine benzer ürünlerin ticaretinin Klasik Dönem'den itibaren süregelmiş olması ihtimali yüksektir.

Rhodos'un daha sonra bu sefer Atina'ya karşı ayaklanma işine giriştiği görülmektedir. Byzantion ve Khios da bu ayaklanmaya destek vermişlerdir. Diodoros (XV. 79. 1), Atina ile Thebesliler arasında düşmanlıkların sürdüğü 364/3 yılında, Thebesli komutan Epaminondas'ın Byzantion, Khios ve Rhodos'a yönelik bir donanma birliğini komuta ettiğini ve bu kentleri Thebeslilerin "kendisi" yaptığını, diğer deyimle onlarla ittifak kurduğunu bildirmektedir. 377 yllından itibaren Atina ile ittifak halinde olan Byzantion, Rhodos ve Khios, Doğu Akdeniz kentleri arasında en önemli ticaret devletleri olduklarından, bir savaş durumunda ekonomik etkinlikleri zarar görecekti. Bu devletler Thebeslilerle ittifaka girerek ve Atina gemilerine limanlarını kapatarak bir savaş çıkmasını önlemeyi planlamış olmalıydılar. Bu noktada, aşağıda değineceğimiz, Byzantion, Khios ve Rhodos ayaklanmaları Thebesli Epameinondas tarafından 364/3 yılından itibaren ivme kazandırılan ve devam eden ayaklanmalar olmuştur ${ }^{23}$. Bu ayaklanmaların başlamasının asıl sebebi ise, 377 'de kurulan İkinci Atina Konfederasyonu olaylarında Atina çıkarlarının, daha doğrusu emperyalist emellerinin öne çıkmasıdır ${ }^{24}$.

Demosthenes, Leptines'e Karşı (XX) yaptığı 357 yılındaki mahkeme konuşmasında aynı yıl Atina'nın hububat kıtlığı çektiğini bildirmektedir. Bu kıtlı̆ın sebeplerinden birisinin aynı yıl Rhodos'un diğer devletlerle birlikte Atina'ya karşı ayaklandığı Sosyal Savaş olması ihtimali yüksektir. Bu sözde Sosyal Savaş sırasındaki Rhodos'un oynadığı rol önemlidir. Dolayısıyla, döneminin Rhodos ekonomisi ve siyaseti açııından bu savaşın özellikle üzerinde durulması gerekmektedir.

Atina, 357/356 ve 355/354 yılları arasında üç yıl süren ${ }^{25}$ bu savaşı İkinci Atina Konfederasyonu'nun ayaklanan üyelerine karşı yürütmüş ve savaş birliğin en varlıklı üyeleri olan Byzantion, Khios ve Rhodos'un kesin olarak kontrolden çıkmasıyla sonuçlanmıştır. Bu ayaklanmaların sebepleriyle ilgili olarak, aşağıda değineceğimiz Demosthenes'in bildirdiği Atina karşısındaki birlik üyelerinin şikâyetleri (XV. 15) veya onun Karia satrapı Mausolos'un hırslarına karşı alınması gereken önlemlerle ilgili ikazları önemlidir. Dolayısıyla Atina emperyazliminin canlanmasına karşı tepkiler ve Karia satrapı Mausolos'un müdahalesi sonucunda bu ayaklanmaların meydana geldiği iddiası öne sürülebilir.

Demosthenes, 351 yılına tarihlendirilen Rhodos/uların Özgürlüğü Üzerine adlı konuşmasında şöyle bildirmektedir (XV): "[3] Çünkü Khioslular, Byzantionlular ve Rhodoslular bizi kendilerine karşı kumpas kurmakla suçladılar ve bu sebeple son savaşta [Sosyal Savaş] bize karşı işbirliği yaptılar; fakat biz, meselenin baş müsebbibi ve kışkırtıcısı Mausolos'un, kendisini Rhodosluların dostu olarak çağırırken onları özgürlüklerinden ettiğini, Khiosluların ve Byzantionluların onların [Rhodosluların] müttefikleri olarak tavır takınırken sıkıntıları anında onlara asla yardım etme-

22 Triantafyllidis 2003.

23 Sealey 1976, 439; Ruzicka 1998, 65-8.

24 Rhodos'un 377 yılında İkinci Atina Konfederasyonu'na katıldığı bilinmektedir. Atina Konfederasyonu'na katıldığında Rhodos'a demokratik bir yönetim hâkimdi ve Demosthenes'in "Rhodosluların Özgürlüğü Üzerine" başlıklı konuşmasından anlaşılacağı üzere, 357 yılında Atina'ya karşı ayaklandığında demokratik yönetimin devam ettiği görülmektedir (Hornblower 1982, 125-7). Atina eski gücüne kavuşmak için özellikle Byzantion, Rhodos ve çevresinde kontrolü sağlamak zorundaydı. V. ve IV. yüzyılda Mısır ve Karadeniz ticaret yolunun Atina açısından özellikle kriz dönemlerindeki önemi için bk. Garnsey 1988, 120-39, 142-64.

25 Diod. XVI. 7. 3; daha detaylı bilgi için bk. Arslan 2010, 163 vd. 
diklerini, sizden korktuklarını, bütün devletler içinde kurtuluşlarını sadece size [Atinalılara] borçlu olduklarını ispatıyor olacağız".

Demosthenes konuşmasında, Sosyal Savaş'tan sonra oligarkların Rhodos'ta demokratik yönetimi devirmesiyle, Atina'ya kaçan veya sürgüne gönderilen Rhodoslu demokratların isteği üzerine Atina meclisini Rhodos'a müdahale etmeye ikna etmeye çabalamaktadır (XV. 2. 14). Atina'nın Rhodos'a müdahale etme teklifini Rhodoslu demokratların çıkarı için yapmadığını, gerçekte Rhodos'taki demokrat parti ile bir ilişkisi olmadığını ve yardım talebinde bulunanların hiçbirisinin aslında kendi yakın arkadaşı olmadığını iddia ederek (XV. 15), Demosthenes'in özellikle bu konuda kendisini savunma gereği duyması ilginçtir. Rhodos'tan sürülen bu demokratlar ayaklanma sonucunda gerçekleşen oligarşik devrim sonucunda ekonomik zarara uğramış olmalıydılar. Bunların çoğunluğu, deniz tiracetinden büyük gelirler elde edenlerden oluşmalıydı. Demosthenes de Rhodos'tan sürülerek Atinalılardan yardım isteyen bu demokratlarla bir çıkar ilişkisi içinde olabilirdi ${ }^{26}$. Daha genelde ise, Atina Devleti de Rhodos'u kontrol edemediğinden dolayı ticari alamda zarar görmekteydi. Zira yukarıda belirtildiği ve yine aşağıda açıklanacağı gibi, Atina hububatının önemli bir kısmını Mısır-Rhodos rotası üzerinden sağlamaktaydı. Dolayısıyla Demosthenes'in bunların yerine meseleyi, Rhodosluların özgürlüğüne kavuşması kavramı altında ele alarak insani gibi gözüken, ancak ikiyüzlü duygularını ön plana çıkarması intimali bulunmaktadır²7.

Demosthenes yine bahsi geçen konuşmasında (XV. 15) Rhodoslu demokratların serzenişte bulunarak Atinalıların kendilerini "kendi hakları olandan" esirgediklerini bildirmektedir. Zira

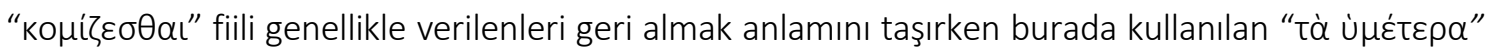
ise Atina'nın V. yüzyıl imparatorluğunun mal ve mülklerine karşılık gelmektedir ${ }^{28}$. Daha özele indirgemek gerekirse, Rhodos'taki oligarşik devrim sonucunda burada bulunan Atinalıların (XV. 5), özellikle Atinalı tüccarların mallarına ve mülklerine ve hatta alacaklarına el konmuş olmalıydı. Bu durumda Rhodoslu oligarklar Atina ile ticaret yapan tüccarların Rhodos limanlarını ücretsiz kullanması imkânını da ortadan kaldırmış olmalıydı.

Illgili kaynaklar yeniden incelendiğinde Sosyal Savaş'tan sonra Rhodos'taki oligarşik devrimin iç çekişmeler sonucunda meydana geldiği söylenebilir. Yukarıda değindiğimiz üzere, değişen iç ve dış dinamikler paralelinde IV. yüzyılın ilk yarısında Rhodos'ta sık sık devrimlerin olduğu bir gerçektir. Demosthenes, "Rhodosluların Özgürlüğü" adlı konuşmasını yaptığı 351 yılında, Rhodos'un tekrar oligarşiye döndüğüne açıkça değinmektedir (XV. 19). 353/2 yılına tarihlendirilen konuşmasında da Rhodos'ta demokrasinin yıkıldığından tesadüfi olarak bahsetmektedir. ${ }^{29}$ Bu durumda Rhodos, aşağıda bahsedeceğimiz, Karia kraliçesi II. Artemisia'nın tahta çıktığı 353 yılı itibariyle oligarşiye dönmüştü. Aristoteles de Politika adlı eserinde büyük bir ihtimalle Rhodos'taki bu oligarşik devrime değinmektedir ${ }^{30}$.

Aristoteles, bir önceki paragrafta da aynı olaya atfen Rhodos halkı arasındaki çıkar çekişmelerini ele almaktadır ${ }^{31}$. Burada demokratik hükümetin getirdiği sert yükümlülükler sonucunda kamu borçları doğan Rhodoslu varlıklı demogoglarla gemilerin tamiri veya belkide mürettebatına

26 Demosthenes'in çıkarmış olduğu kanunlar ve kararnamelerle kendisine maddi çıkarlar sağladığı ve rüşvet aldığı hakkındaki suçlamalar için bk. Din. I. 41-45.

27 Dem. XV. 17-22.

28 Cawkwell 1972, 272 dn. 4.

29 XIII. 8.

30 Arist. Pol. V. 1304 B, 28-31.

31 Arist. Pol. V. 1302 B 20 vd. 
olan borçlarını ödemedikleri için kendilerine dava açılan deniz kaptanları (trierarkhoi) arasındaki işbirliğinden söz edilmektedir. Bu demogoglar, varlıklı trierarkhoinin çıkarlarını korumak için mecliste veya mahkemelerde onlar lehine konuşmalar yapmaya başlamışlardı. Bu konuşmalar sonucunda kendi taraflarına önemli bir kitleyi çekmeyi başardıkları ve demokratik hükümeti muhtemelen 354 yılı civarında yıktıkları anlaşılmaktadır.

Yukarıda Aristoteles tarafından da bildirildiği gibi 350'li yılların sonlarında Rhodoslu oligarkların çoğunluğu gemi veya filolarına sahipti. Zenginler sınıfını oluşturan oligarklar normal şartlarda ticaret ile iştigal olurlarken Sosyal Savaş’ın getirdiği yükümlülüklerle ekonomik zorluklar içine girmişler ve kamu borçlarını ödememek için Rhodos'taki bu oligarşik devrimi gerçekleştirmişlerdir. Rhodos, Sosyal Savaş esnasında yüz yelkenli gemiden oluşan ayaklanma donanmasına katkıda bulunarak belli bir yükümlülük altına girmişti ${ }^{32}$. Donanma gemilerinin donanımını sağlamak büyük bir maddi harcama gerektirdiğinden, bu varlıklı vatandaşlardan sağlanmaktaydı. Bu durum nihayetinde onların demokratik hükümeti devirmelerine yol açmış olmalıdır. Yönetimi ele geçiren Rhodoslu oligarkların zararlarını telafi etmek için zengin kaynaklara sahip Halikarnassos'a gözlerini dikmeleri söz konusu olabilir ${ }^{33}$.

Sadece Vitruvius (II. 8. 14-15), Mausolos'un 353/2 yılında ölümünden sonra eşi II. Artemisia'nın tahta çıkması sonucunda Rhodos'u ele geçirdiğine değinmektedir. Karşı görüşler söz konusu olsa da, bu olayın vuku bulma intimali dikkate alınmalıdır. Aslında Demosthenes'in "Rhodosluların Özgürlüğü Üzerine" adlı konuşmasının içeriği detaylı incelendiğinde (XV. 8), bu konuşma içinde II. Artemisia'nın Pers kralı ile işbirliği yaparak Rhodos'u ele geçirdiğini ima eden deliller bulunmaktadır. Ayrıca Demosthenes tarafından aynı konuşmada aktarılan bir diğer paragraf (XV. 27), II. Artemisia'nın Rhodos'u ele geçirdiğine işaret etmektedir. II. Artemisia 351 yılında da Rhodos'a hakim gözükmektedir (XV. 12). II. Artemisia'nın yönetimi sırasında bazı kentleri değişik taktikler uygulayarak ele geçirdiğini teyit eden bir diğer kaynak bu bağlamda dikkate alınmalıdır ${ }^{34}$. Sonuçta, II. Artemisia kentleri ele geçirmek için değişik taktikler uygulamaktaydı ve Rhodos'u da Perslerin rızasıyla ele geçirmiş olması intimalinin dikkate alınması gerekmektedir.

II. Artemisia'nın Rhodos'u ele geçirmesinden sonra, Rhodos adası ile ilgili antik kaynaklar sessizliğini korumaktadır. Daha sonra Makedonya kralı II. Philippos'un 339 yılında Byzantion'u kuşatması sırasında bölgeden geçen önemli sayıda ticaret gemisine el koyması Rhodos'un da tepkisine yol açmıştır. Diodoros (XIV. 76. 2-3), sadece Atinalıların değil aynı zamanda Khios, Kos, Rhodos ve bazı diğer kentlerin de II. Philippos'un saldırısı karşısında Byzantion'a yardım etmek için ek güçler gönderdiğini bildirmektedir. Bu olay, Byzantion'un ele geçirilmesinin, Karadeniz üzerinden konvoylarla yapılan ithal ticaretinin tehlikeye düşmesi durumunda, Rhodos da dâhil diğer kentleri askeri anlamda harekete geçmeye sevk edecek kadar alarm verici olduğu anlamına gelmektedir.

Büyük İskender'in ölümünün ardından Mısır yöneticisi olarak kötü bir ün bırakacak olan Kleomenes, 330 yılı civarında bazı sert uygulamalarıyla suni bir şekilde uluslararası marketteki hububat fiyatınının yukarı çekilmesine yol açmıştır. Önemli olan nokta, Rhodos'un onun operasyonlarının merkezi olmasıdır. Demosthenes, Mısır üzerinden gelen ticaret bağlamında Rhodos'un ne kadar önemli olduğunu vurgulayan önemli bir delil sağlamaktadır. Dionysodoros Karşısında (LVI) başıkıkı mahkeme konuşmasında bir hububat tüccarı ve onun ortağı hakkında şahsi bir olayı

32 Diod. XVI. 7. 3, 21.2.

33 Vitruvius (I. 2. 8. 11), Halikarnassos'un bir ticaret merkezi olması ve iyi bir limana sahip olması nedeniyle Mausolos'un başkentini Mylasa'dan Halikarnassos'a taşıdığını bildirmektedir.

34 Polyain.strat. VIII. 53. 4. 
aktarmaktadır. Bu olay, yine bir kriz döneminde Atina ve Aetolia Birliği'nin Makedonya ve onun müttefiki Boetia'ya karşı gerçekleştirdiği Lamia Savaşı (323-322) sırasında geçmektedir. Demosthenes kendisi ve diğerlerinin, Dionysodoros adlı birisine (metikoiden) kıtlık zamanında Mısır'dan hububat sağlaması ve limana getirmesi için nasıl para ödünç verdiğine dair bir anlatımda bulunmaktadır. Ancak anlaşma planlandığı üzere gitmemiş, iki iddia edilen suçlu para ödünç verme anlaşmasını bozmakla kalmamış aynı zamanda Atina hububat ticaretini yöneten en sert kanunların birkaçını çiğnemişlerdir. Demosthenes'in iddiasına göre, Dionysodoros ve ortağı Parmeniskos Sicilya'dan hububat gelmesi üzerine Atina'da hububat fiyatları düşünce hububatı Atina'ya getirmemişler, Mııır'dan getirilen yükü Rhodos'ta indirerek daha yüksek fiyata satmışlar ve anlaşmayı bozmuşlardır (LVI. 7-10). Yükü Atina'ya getirmiş olsalardı kredi verenler daha fazla faiz alabileceklerdi. Bunu yapmalarının Atina kanunlarına göre suç olduğu bildirilmektedir. ${ }^{35}$ Aslında Atina bu yiyecek kıtlığı döneminde hububat getirmek için kredi verilen ticaret gemilerinin Atina limanı Piraeus dışında başka bir yere yükünü boşaltmasını yasaklamış ve bunun denetimi için 10 denetçi görevlendirmişti. Dolayısıyla Karadeniz dışında Mısır ve Sicilya hububat ithali için önemli merkezlerdi ve hububat Mısır'dan Atina'ya Kıbrıs veya Rhodos üzerinden gelmekteydi. Gerçekte suçlananların kargolarını Rhodos'ta boşaltmalarının sebebi Mısır'a sefere riskli bir dönemde başlamış olmaları olabilirdi. Onların yaklaşık olarak Auğustos ayında seferlerine başladıkları gözükmektedir. Bu dönüş yolunda, riskli Eylül, Ekim ve Kasım aylarında seyehat etmek anlamına gelmekteydi. Seyehat Kasım ayını geçtiğinde çok daha tehlikeli olacaktı. Dolayısıyla yelken açma sezonunda gecikme olduğundan ve kargoyu tehlikeye atmak istemediklerinden önceden de akıllarında olan ancak kredi verenlerin kabul etmedikleri Rhodos'ta yüklerini boşaltıp satmayı tercih etmiş olabilirlerdi. Aslında Dionysodoros'un, geminin İskenderiye'den yola çıktıktan sonra hasar gördüğünden Rhodos'ta karaya çıkmak zorunda olduğunu iddia ettiği de bildirilmektedir. Dionysodoros, doğruyu söylediğini ispatlamak için de kargolarının bir kısmını Atina'ya taşımak için Rhodos'ta bazı gemiler kiraladığını bildirecektir. Diğer taraftan Atina'da olduğu gibi Rhodos'ta da kıtlık yüzünden benzer bir kanunun olması söz konusu olabilirdi. Belki bu yüzden de Dionysodoros'un kargosunu Rhodos'ta boşaltmaya zorlanması ihtimali göz ardı edilmemelidir $^{36}$. Bu durumu teyit eder şekilde birkaç diğer antik kaynak, kentlerin başka limanlara hububat taşıyan gemileri alıkoyabileceğini ve kargolarını satmaya zorlayabileceğini göstermektedir ${ }^{37}$.

Büyük İskender'in ölümünün ardından siyasi bölünmeler esnasında Attalos ve askerleri Knidos, Kaunos ve Rhodos'a saldırmış ve girmiş oldukları deniz savaşında Rhodosluların amirali Demeratos, onları geri püskürtüp tam bir yenilgiye uğratmıştır ${ }^{38}$. Antipatros, 321 yılında I. Antigonos'u Asya ordusu başkomutanlığına atamıştır. I. Antigonos, zamanla Anadolu'yu bütünüyle denetimi altında almıştır. Ancak Mısır kralı I. Ptolemaios, Lysimakhos, Kassandros ve Seleukos, I. Antigonos'un İskender'in imparatorluğunu yeniden birleştirme tasarısını engellemek amacıyla aralarında birleşerek ilk koalisyon savaşını (315-311) başlatmışlardır. Bunun üzerine Agesilaus'u Kıbrıs'taki kralların üzerine, Idomeneus ve Mosshion'u Rhodos'a ve yeğeni Polemaios'u Amisos'a karşı savaşmaları için gönderen I. Antigonos, Kassandros'un Kapadokya'yı istila eden ordusunu defetmek için de Kapadokya'ya bir ordu göndermiştir. Polyperkhon'un oğlu Aleksandros ile dostluk kuran I. Antigonos, Kassandros'a karşı savaş başlatmışıır ${ }^{39}$. Daha savaşın ilk yılında,

35 Atinalıların Rhodos'ta hukuki davalara katılmalarıyla ilgili olarak ayrıca bk. Dem. XXXII. 18; ILV. 64; LVI. 47.

36 Ayrica bk. Arist.Oek. 1348 b 33 vd.

37 Ayrica bk. Dem. L. 6.

38 Diod. XVIII. 37. 3-4; Phot. bibl. XCII. 11

39 Diod. XIX. 57. 1-5. 
315 yııında, Seleukos'un donanmasının komutanı Polykleitos, Kıbrıs'tan Pamphylia kıyılarına kadar düşmanı kolladıktan sonra, kıyı boyunca Kilikia'daki Aphrodisia'ya doğru gitmekteyken I. Antigonos'un amirali Theodotos'un Lykia'daki Patara kentinden denize açıldığını öğrenmiştir. I. Antigonos donanması, Rhodos gemilerinden ve Karialı tayfalardan oluşmaktaydı ${ }^{40}$.

I. Ptolemaios, I. Antigonos'a karşı savaşta kendisine katılması için Lysimakhos ve Kassandros'un etkisindeki Hellen kentlerinden yardım istemiştir. I. Antigonos, oğlu Demetrios'u Kilikia'ya göndermiş ve Demetrios, I. Ptolemaios'un generallerini yenmiş, kentleri geri almıştır ${ }^{41}$. I. Ptolemaios, 309 yılı baharında kendi generallerinin Kilikia kentlerini kaybettiğini duyunca ordusuyla Phaselis'e yelken açmış ve bu kenti ele geçirmiştir. Phaselis alındıktan sonra Lykia'ya geçerek Ksanthos'u almıştır. Ayrıca, Kaunos, lasos ve Myndos kentlerini de ele geçirmiştir ${ }^{42}$. Ancak Demetrios'un zamanında müdahale etmesiyle Halikarnassos'u ele geçirmekte başarısız olmuştur ${ }^{43}$. Demetrios, $309^{\prime}$ un sonu ve 308'de I. Ptolemaios'un ele geçirdiği Karia ve Lykia kentlerini geri almış olmalıdır. Daha sonra, 306 yılında babasının verdiği emirlere uyarak Karia'ya yelken açmıs ve orada Rhodosluların Ptolemaioslarla bağlantııını koparma faaliyetlerine girişmiştir. ${ }^{44}$

Bu sırada Rhodoslular iyi niyet sergileyerek özellikle I. Ptolemaios'a meyillenmişlerdir, çünkü yukarıda da belirttiğimiz üzere gelirlerinin çoğu Mısır'a yelken açan tüccarlardan gelmekte ve genellikle kent, yiyecek erzakını o kralıktan sağlamaktaydı ${ }^{45}$. I. Antigonos bunu bildiğinden, Rhodosluların I. Ptolemaios ile bağlantılarını kopartmak niyetiyle, ilk önce I. Ptolemaios'a karşı Kıbrıs için savaştığı sırada, elçiler göndererek Rhodos'un kendileri ile ittifak yapmasını ve Demetrios'a eşlik edecek gemiler göndermesini istemiştir. Demetrios, Rhodosluların razı olmaması üzerine, generallerinden birisini gemiyle göndererek Rhodos'tan Mısır'a yelken açan tüccarların her birini karaya çıkartarak yüklerine el koyma emrini vermiştir. I. Antigonos generali Rhodoslular tarafından geri püskürtüldüğünde güçlü birlikleriyle kentlerini kuşatma tehdidinde bulunmuştur. Buna rağmen Rhodoslular, ona elçiler göndererek I. Antigonos'un kendilerini I. Ptolemaios'a karşı bir savaş içine hızla sokmaya zorlamaması için yalvarmışlardır. Rhodoslular I. Antigonos oğlu Demetrios'u daha güçlü bir ordu ile gönderdiğinde, elçiler göndererek I. Ptolemaios'a karşı savaş için I. Antigonos'a katılabileceklerini söylemişlerdir. Ancak Demetrios, en soylu Rhodos vatandaşlarından 100'ünü rehin olarak istemiş ve aynı zamanda donanmasının Rhodos limanlarına kabul edilmesini talep etmiştir. Bunun üzerine Rhodoslular, kentlerine komplo kurulduğunu düşünerek savaşa hazırlanmak zorunda kalmışlardır. Nihayetinde 305/4 yılında ünlü Rhodos kuşatması başlamıştır ${ }^{46}$. Demetrios, ancak bir yıl süren uzun bir kuşatma ve zorlu çatışmalar sonrasında Rhodoslulara anlaşma koşullarını kabul ettirebilmiştir. Buna göre Rhodos, özerk ve garnizonsuz kalmak şartıyla kendi gelirlerine sahip, I. Ptolemaios ile yapılan savaşlar haricinde I. Antigonos'un müttefiki olacak ve Demetrios'un seçtiği vatandaşlarından 100 tanesini rehine olarak verecektir ${ }^{47}$. Demetrios'un bütün zorluklara rağmen Rhodosluları anlaşma koşullarını kabul ettirme yönündeki ısrarı adanın stratejik önemini bir kere daha gözler önüne sermektedir.

Diod. XIX. 64. 4-8

41 Diod. XX. 19. 3-5.

42 Diod. XX. 27. 1-2; 37.1.

43 Plut. Dem. VII. 3.

44 Büyük İskender sonrası adadaki siyasi gelişmeler hakkında bk. Van Dessel-Hauben 1977, 309 vd.

45 Diod. XX. 81. 2-4. Ptolemaios krallı̆̆ının deniz hâkimiyeti politikası için bk. Hauben 2013, 39-65.

46 Plut. Dem. XX. 9.

47 Diod. XX. 95. 1-100. 1. 


\section{Sonuç}

Rhodos Arkaik Dönem'den itibaren güçlü bir askeri donanmaya ve deniz ticaretiyle uğraşan tüccar sınıfına sahip ola gelmiştir. Bu durum adanın refah seviyesine yansımıştır. V. yüzyıl Rhodos ekonomisi ve siyaseti hakkında pek fazla edebi, yazılı kaynak bulunmamaktadır. Çok az olan bu kaynaklar genellikle Atina merkezli olup, V. yüzyılın ortalarında yazan Herodotos dahi Rhodos adasındaki kent devletleri hakkında pek fazla bilgi vermemektedir. Rhodos, özellikle Ege ve Karadeniz'den gelerek Güney Anadolu sahilleri ve Levant üzerinden Mısır'a giden ticaret rotaları üzerinde oldukça önemli bir stratejik konuma sahip olmuştur. Klasik dönemde Persler, Spartalılar ve Atinalılar gibi bölgenin büyük güçlü devletleri arasında denge politikaları sayesinde ayakta kalmayı başarmıştır. V. yüzyılın son çeyreğinde Peloponnesos savaşlarının stratejik ticaret yollarının geçtiği Anadolu kıyılarına kaymasıyla, bu savaş hakkında bize detaylı bilgiler sağlayan Thukydides sayesinde Pers-Sparta ve Atina kent devletleri güç ekseninde arada kalan Rhodos ile ilgili olarak yine satır aralarından da olsa bazı önemli bilgiler edinebilmekteyiz. Rhodos'un özellikle IV. yüzyılda Rhodos içinden de destek alan bu büyük güçlerin etkisi altında sık sık taraf değiştirdiğine ve hatta Atina'nın desteklediği demokrasiden, Pers ve Spartalıların desteklediği oligarşiye kaydığına şahit olmaktayız. Ticaret gemileri Rhodos adasını önemli emporion’lardan birisi olarak görmekte, gerektiğinde Byzantion gibi depolama merkezi olarak kullanılan burası yakın bölgesi itibariyle de ticari açıdan belli bir önem arz etmektedir. Klasik dönem Rhodos'u özellikle uluslararası hububat ticaretinde en önemli merkezlerden birisi olmuştur. Bölgeden geçen ticaret gemilerinin güvenliği açısından da Hellenler adına korsanlarla savaşı üzerine almış ve korsanlardan denizleri temizlemiştir. Dolayısıyla Rhodos ve Kıbrıs, Arkaik Dönem'den itibaren Anadolu'nun, deniz ticareti bağlamında Batı'dan ve özellikle Karadeniz üzerinden Mısır ve Mısır üzerinden Afrika'ya açılan ve güvenliği öne çıkan kapısı olmuştur. Ancak bu durum Rhodos'ta dahîl 12 adaların Hellas'a verilmesi ve Kıbrıs'ın ikiye bölünmesiyle engellenmiştir.

Rhodos, IV. yüzyıın sonlarına doğru Büyük İskender sonrası Diadokhoi krallarının hırsla elde etmek istedikleri cazibe merkezi olmuştur. Rhodos başlangıçta ticari çıkarları açısından avantajlı olacağını düşünerek Hellenistik Dönem hanedanlarının her biri ile dostluklar kurmaya çabalamıştır. Bunun sonucunda onların her biri tarafından kraliyet hediyeleriyle onurlandırılmış ve uzun süre barış ortamından yararlanarak büyük adımlar atmıştır. Ancak 305 yılında Makedonya kralı I. Antigonos'un oğlu Demetrios'un ısrarlarına rağmen, kendi ticareti ve gelirleri açısından önemli bir yer olan Mısırın safında yer almış, bu durum adanın teslim olmasıyla son bulmuştur. 


\section{BİBLIYOGRAFYA}

\section{Antik Kaynaklar ve Kısaltmalar}

Aristot. Oek.

Aristot. pol.

Arr. anab.

Ath. Deip.

Din.

Dem.

Diod.

Ksen. Hell.

Liv.

Lyk.

Paus.

Phot. bibl.

Plut.Dem.
(= Aristoteles, Oekonomika)

Aristotle. Aristotle in 23 Volumes, Vol. 18, translated by G.C. Armstrong. Cambridge, MA, Harvard University Press; London, William Heinemann Ltd. 1935.

(= Aristoteles, Politika)

Aristotle in 23 Volumes. With an English translation by H. Rackham, vols. XXI. Cambridge, Mass.- London 1944 (The Loeb Classical Library).

(= Arrianus, Anabasis)

Arrian. With an English translation by P. A. Brunt, vols. I-II. Cambridge, Mass.London 1976-1983 (The Loeb Classical Library).

(=Athenaios, Deipnosophistai)

The Deipnosophists. With an English translation by C. B. Gullick, vols. I-VII. Cambridge, Mass.- London 1927-1999 (6).

(= Dinarkhos)

Dinarkhos. Minor Attic Orators in two volumes, 2. With an English translation by J. O. Burtt, M.A. Cambridge, MA, Harvard University Press; London, William Heinemann Ltd. 1962.

(= Demosthenes)

Demosthenes. Speeches 11-20. With an English translation by C. A. Vince, M. A. and J. H. Vince, M.A. Cambridge, MA, Harvard University Press; London, William Heinemann Ltd. 1926 (The Loeb Classical Library).

Demosthenes. Speeches 51-61. With an English translation by N. W. De Witt N. J. De Witt. Cambridge, Mass.- London 1949 (The Loeb Classical Library).

(= Diodorus Sicilus, Bibliotheke Historike)

Diodorus of Sicily. With an English translation by C. H. Oldfather, vols. I-VI; C. H. Sherman, vols. VII; C. B. Welles, vols. VIII; R. M. Geer, vols. IX-X; F. R. Walton, vols. XI-XII. Cambridge, Mass.- London 1933-2004 (7) (The Loeb Classical Library).

(= Ksenophon, Hellenika)

Xenophon. Xenophon in Seven Volumes, 1 and 2. Carleton L. Brownson. Harvard University Press, Cambridge, MA; William Heinemann, Ltd., London. vol. 1:1918; vol. 2: 1921.

(= Livius, Ab Urbe Condita)

Livy. History of Rome. With an English translation by Rev. C. Roberts. Cambridge, Mass.- London 1912 (The Loeb Classical Library).

Titus Livius, Roma Tarihi: Şehrin Kuruluşundan Itibaren. Çev.: S. Şenbark. İstanbul $1992 \mathrm{vd}$.

(= Lykurgos)

Lycurgus. Minor Attic Orators in two volumes, 2, with an English translation by J. O. Burtt, M.A. Cambridge, MA, Harvard University Press; London, William Heinemann Ltd. 1962.

(= Pausanias, Perihegesis tes Hellados)

Description of Greece. With an English translation by W. H. S. Jones - H. A. Ormerod, vols. I-IV. Cambridge, Mass.- London 1918.

(= Photios, Bibliotheke)

Photios. Bibliotheka. Edited by R. Henry, Paris 1971.

Photius. The Bibliotheca. A selection translated with notes by N. G. Wilson. London $2002^{2}$.

(= Plutarkhos, Demetrios)

Plutarch. Plutarch's Lives. With an English Translation by B. Perrin. Cambridge, Mass.- London, vols. I-II: 1914, vols. VII: 1919 (The Loeb Classical 
Polyain. strat.

Polyb.

Strab.

Thuk.

Vitr. De Arch.

Modern Literatür

Abulafia 2014

Arslan 2010

Ball 1977

Braund 1993

Berthold 1984

Bruce 1961

Casson 1954

Cawkwell 1972

Cawkwell 1981

David 1984

Gabrielsen 1997

Garnsey 1988

Gibbins 2001

Kurul 2014

Hauben 2013

Hornblower 1982

Jacoby 1957

Magie 1950

Meiggs 1972
Library).

(= Polyainos, Strategemata)

The Strategems of War. With an English translation by R. Shepherd. Chicago $1974^{2}$.

(= Polybios, Historiai)

Polybius. Histories. With an English translation by E. S. Shuckburgh. London, New York: Macmillan 1889. Reprinted: Bloomington 1962.

(= Strabon, Geographika)

The Geography of Strabo. Edited by H. L. Jones. Cambridge, Mass.- London 1924. (= Thukydides)

Thucydides. The Peloponnesian War. With an English translation by J. M. Dent (London) and by E. P. Dutton (New York) 1910.

(= Vitruvius, De Architectura)

Vitruvius: The Ten Books on Architecture. Vitruvius. With an English Translation by M. H. Morgan. Cambridge: Harvard University Press. London: Humphrey Milford. Oxford University Press. 1914.

D. Abulafia, "Thalassocracies". Eds. P. Horden-S. Kinoshita, A Companion to Mediterranean History. Malden-Oxford (2014) 139-153.

M. Arslan, İstanbul'un Antikçağ Tarihi: Klasik ve Hellenistik Dönemler. İstanbul 2010.

R. Ball, "Karian' Place in Diodoros' Thalassocracy List". Classical Quarterly 27/2 (1977) 317-322.

D. Braund, "Piracy Under the Principate and the Ideology of Imperial Eradication". Şurada: War and Society in the Roman World. Eds. J. Rich and G. Shipley. London: Routledge 1993.

R. M. Berthold, Rhodes in the Hellenistic Age, Ithaca-London 1984.

I. A. F. Bruce, "The Democratic Revolution at Rhodes". Classical Quarterly 11/2 (1961) 166-170.

L. Casson, "The Grain Trade of the Hellenistic World". Transactions and Proceedings of the American Philological Association 85 (1954) 168-187.

G. L. Cawkwell, "Epaminondas and Thebes". Classical Quarterly 22/2 (1972) 254-278.

G. L. Cawkwell, "Notes on the Failure of the Second Athenian Confederacy". Journal of Hellenic Studies 101 (1981) 40-55.

E. David, "The Oligarchic Revolution at Rhodes, 391-89 B.C". Classical Philology 79/4 (1984) 271-284.

V. Gabrielsen, The Naval Aristocracy of Hellenistic Rhodes. Oxford 1997.

P. Garnsey, Famine and Food Supply in the Graeco-Roman World: Responses to Risk and Crisis. Cambridge University Press 1988.

D. Gibbins, "Shipwrecks and the Hellenistic Trade", Eds. Z. Archibald, et al. Hellenistic Economies, London: Routledge (2001) 205-232.

E. Kurul, "Rhodos'luların Denizcilik Yasası". Cedrus II (2014) 527-549.

$\mathrm{H}$. Hauben, "Callicrates of Samos and Patroclus of Macedon, Champions of Ptolemaic Thalassocracy". Eds. K. Buraselis - M. Stefanou - D. J. Thompson, The Ptolemies, the Sea and the Nile: Studies in Waterborne Power (2013) 39-65.

S. Hornblower, Mausolus. Oxford 1982.

F. Jacoby, Die Fragmente der Griechischen Historiker: (FGrH), 17 Vols. Leiden 1957.

D. Magie, Roman Rule in Asia Minor, vol. I. Princeton - New Jersey 1950.

R. Meiggs, The Athenian Empire. Oxford 1972. 
Meritt 1939

Myres 1906

Ruzicka 1998

Selaey 1976

Starr 1989

Tod 1933-1948

Triantafyllidis 2003
B. D. Meritt et al. (eds), The Athenian Tribute Lists I (ATL). Cambridge, Mass. 1939 J. L. Myres, "On the 'List of Thalassocracies' in Eusebius". Journal of Hellenic Studies 26 (1906) 84-130.

S. Ruzicka, "Epaminondas and the Genesis of Social War". Classical Philology 93/1 (1998) 60-69.

R. Sealey, A History of the Greek City States. London 1976.

C.G. Starr, The Influence of Sea Power on Anceint History. Oxford: Oxford University Press 1989.

M. N. Tod, A Selection of Greek Historical Inscriptions I-II. Oxford 1933-1948.

P. Triantafyllidis, "Classical and Hellenistic Glassworkshops from Rhodes". Eds.

D. Foy, M.- D. Nenna. Actes du Colloque de l' AFAV "Echanges et Commerce du Verre dans le Monde Antique., Aix-en-Provence et Marseille, 7-9 Juin 2001, Monographies Instrumentum 24, Montagnac (2003) 131-138.

Van Dessel-H. Hauben 1977 P. van Dessel-H. Hauben, "Rhodes, Alexander and the Diadochi from 333/332 to 304 B.C.", Zeitschrift für Alte Geschichte 26/3 (1977) 307-339. 